\title{
Evaluation and prediction of the sustainable development potential of mountain towns based on ecological footprint
}

\author{
Na AN*, Tongji University, China \\ Binman YANG, Politecnico di Torino, Italy
}

\begin{abstract}
As an effective method to quantify the utilization and evaluate the sustainability of natural resources, the ecological footprint can indicate the degree of dependence of human production activities and live on natural resources. Measuring the sustainable potential of the environmental system in Lushan County, this paper optimizes the original ecological footprint model. It evaluates the sustainable development of Lushan County from 2009 to 2019 and uses the regression equation model to predict the future sustainable development potential of Lushan County. The results showed that from 2009 to 2019, the per capita ecological footprint of Lushan County decreased by $39 \%$, and the ecological carrying capacity decreased by $14 \%$. Although the ecological deficit was still in 2019, it fell by more than 55\% compared with 2009, and the ecological gradually recovered from the deficit. The ecological footprint diversity index remained stable, but the ecosystem development capacity was reduced to $37 \%$. While the ecological stress index has been decreasing year by year, ecological sustainability is still poor here. If the current consumption pattern is maintained, by 2029, the ecological carrying capacity of Lushan County will be further reduced. This area will face the problem of insufficient ecological carrying capacity, and ecological security is not optimistic. Therefore, there is an urgent need to reduce the ecological footprint and increase the ecological carrying capacity, and propose a future ecological development strategy for Lushan County, and provide guidance for the sustainable development of Lushan County in the future.
\end{abstract}

\section{Keywords}

Mountain towns, Ecological footprint, Sustainable development potential, sustainable development prediction, Lushan County

As the shortage of natural resources continues to intensify. At present, the lack of natural resources has become an essential factor limiting human development, and the contradiction between man and nature has become more and more prominent (Sadik, 1997). In addition, China's rich mountain resources and complex ecological environment have created many mountain towns, forming a unique mountain ecology (Victor, 1997). Mountain towns have high ecological sensitivity, weak self-healing ability, and low resistance to interference. They are vulnerable to poor ecology, topography, natural vegetation, and hydrological environment, making the ecological environment extremely susceptible to damage. On the other hand, mountain towns are ecologically complex and fragile. Once damaged, they are challenging to restore within a short period, which seriously limits the healthy development of mountain towns.

The ecological footprint model was first proposed by William E. Rees and M. Wackernagel (Wackernagel\& Rees, 1998; Wackernagel\&Yount,1997). Its primary function is to quantitatively measure and calculate 
the human consumption of resources at a given population and economic scale. The ecological footprint was developed by V. Niccolucci et al. With the development of ecological footprint theory, the ecological footprint method has been widely used in academic circles, and its research is mainly divided into the following aspects: firstly, ecological footprint models at different scales and the ecological footprint models have gradually moved from the global scale (Niccolucci, 2009) and national scale (Xu, 2003) to the regional scale(Xu, 2003)and town scale (Haberl, 2004); secondly, ecological footprint models of different categories, and the ecological footprint models have gradually been extended to tourism (Wang, 2001). The third is the updating of ecological footprint calculation methods, such as the integrated method based on the net consumption of a specific region $(\mathrm{Wu}, 2006)$, the component method through field surveys and questionnaires( $\mathrm{Wu}, 2006)$, and the input-output method based on the net consumption of resources(Barrett, 2003). The fourth is the link between ecological footprint modelling and sustainability. For example, Shut'ko, Larisa, using the model of the Kuzbass, confirms the importance of an approach to improving economic sustainability through an 'ecological and carbon footprint' (Wiedmann, 2006).

On the whole, most of the current ecological footprint studies pay little attention to the dynamic change process of the ecological footprint, and there are not many studies on the prediction of the sustainable development capacity of ecologically fragile areas such as mountain towns. Therefore, this paper takes the ecologically sensitive mountain town Lushan County as an example. Based on studying the traditional ecological footprint model, this paper improves old data, single factors and insufficient land function. Constructs an improved ecological footprint model measurement to update the primary data, processing the localization of factors and expanding the land function, which is significant to the ecologically sustainable development of mountain towns represented by Lushan County.

\section{Case study area}

Lushan County is located on the west side of the Sichuan Basin, northeast of Ya'an City, with 1,166 square kilometres. The overall ecological base is quite good. The terrain is complex, with widely distributed high, middle, and low mountains and river valley terraces. The landscape is dominated by the central mountain belt, which accounts for about $73 \%$ of the total area, and the high mountain and low mountain belt and flat dams account for about $27 \%$ of the entire region. The overall ecological environment foundation is good. The terrain is complex, the water system is also vibrant, and the abundant natural resources. The land has excellent potential for development.

On April 20, 2013, a magnitude 7.0 earthquake occurred in Lushan County with a focal depth of $13 \mathrm{~km}$. The seismic zone is located in the Longmen mountain fault zone (Su et al., 2013, p. 502) (Figure 1). It has caused significant damage to the ecology of Lushan County and urgently needs post-disaster ecological restoration.

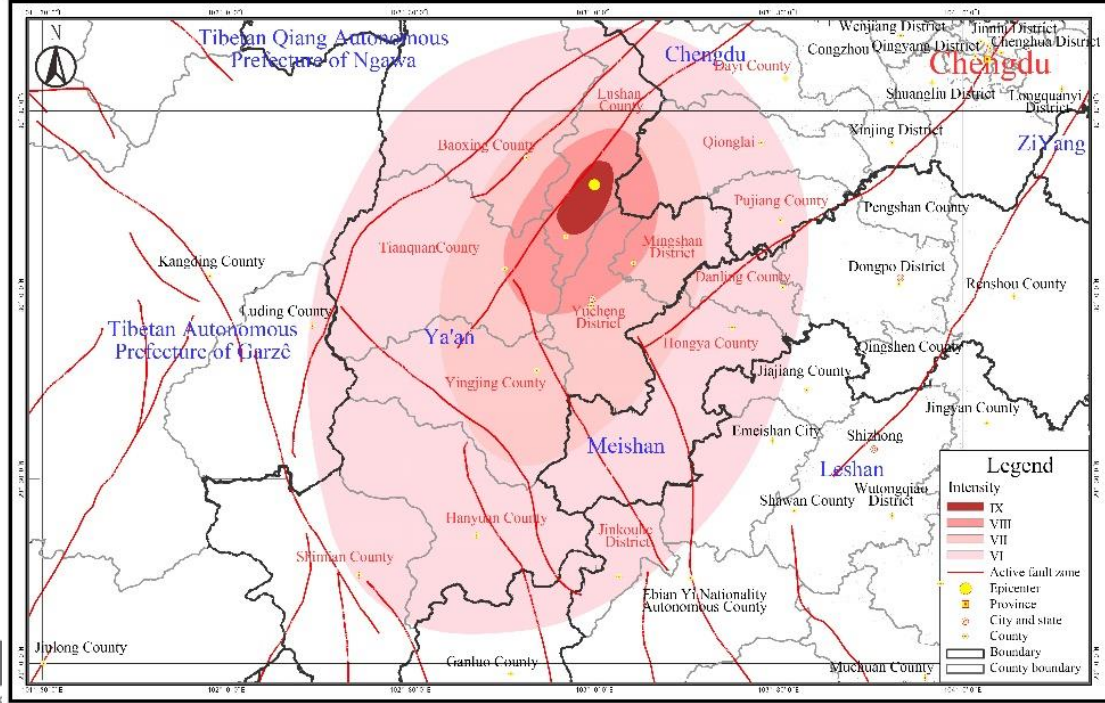


Figure 1. Lushan seismic intensity map. Source: China Seismological Bureau

\section{Research methods}

\subsection{Traditional ecological footprint}

Rees and Wackernagel designed the traditional ecological footprint model (Wackernagel\& Rees, 1998; Wackernagel\&Yount,1997).to calculate the resource consumption and biological production area required to maintain a given population and economic scale based on the consumption of certain ecological products and resources. In mutually exclusive land space, namely, single land production, each human biological consumption is reflected in productive land area. The calculation formula of ecological footprint is as follows:

$$
E F=\sum_{i=1}^{n} C i \cdot E Q i / E P i
$$

Where:

EF stands for an ecological footprint ( $\mathrm{Ha})$,

Ci stands for resource consumption,

EQi stands for the equilibrium factor,

EPi stands for the global average (including arable land, woodland, grassland, construction land, fossil fuel land, and water area).

Ecological carrying capacity refers to the maximum population that can be fed in a specific area without interfering with the normal development of the regional ecological environment. According to a study by WCED (World Committee on Environment and Development), 12\% of the biological production area must be reserved for biodiversity. The calculation formula is as follows.

$$
E C=\sum_{i=1}^{n}\left(A_{i} E Q F_{i} Y F_{i}\right) \cdot(1-12 \%) \quad \mathrm{i}=(1,2,3,4 \ldots 6)
$$

Where:

EC stands for ecological carrying capacity $\left(\mathrm{hm}^{2}\right)$,

Ai represents the area of the class I ecosystem,

EQFi represents the equilibrium factor;

YFi represents the yield factor.

The difference between the supply of natural ecosystems and the consumption of the human economic system can reflect the sustainability of the ecological environment. This difference represents the ecological deficit or surplus, and the formula is as follows:

$$
E D / E R=E C-E F
$$

Where:

ED stands for the ecological deficit,

ER stands for ecological surplus.

EC stands for the ecological footprint,

EF stands for ecological carrying capacity.

If $E D>0$ indicates ecological surplus; When $E D<0$, ecological deficit occurs. 


\subsection{Improved ecological footprint model}

Ecological footprint can intuitively calculate the degree of ecologically sustainable development. Still, the traditional ecological footprint model lacks the multi-consideration of land function, variability of calculation factors, and continuity of repair time sequence. Therefore, an improved ecological footprint model is proposed in this paper to construct the enhanced ecological footprint model (Figure.2) by modifying the original data, localized factor processing, expanded land function(Huang,2008), and the addition of space-time continuity. To measure the ecological footprints over the years makes the evaluation scope more popular, the evaluation subjects more accurate, and the allocation of resources more reasonable.

$E F G=E F+E F n+E F W=\sum_{i=1}^{n} \frac{C i}{E P i} E Q i+\frac{Q C}{A C} E Q i+\frac{W}{P} \times \gamma w$
$E C G=E C+E C W=\sum_{i=1}^{n}($ AiEQiYFi $) \times(1-12 \%)+0.4 \times \psi \times \gamma \times \frac{Q}{P}$

$E D^{\prime} / E R^{\prime}=E F G-E C G$

Where,

EFG refers to the improved ecological footprint,

EF refers to the conventional ecological footprint,

EFn refers to the pollutant ecological footprint,

EFW refers to the ecological water footprint,

ECG refers to the improved ecological carrying capacity,

EC refers to the conventional ecological carrying capacity,

ECW refers to the water ecological carrying capacity,

$E D$ ' refers to the enhanced ecological deficit and,

ER' refers to the improved ecological surplus.

\section{Calculation of improved ecological footprint in Lushan County}

\subsection{Improved ecological footprints of Lushan County, 2009-2019}

According to the improved ecological footprint calculation model, the enhanced ecological footprint of Lushan County over the years is calculated as follows (Figure 2). The data are from the Statistical Yearbook of Ya 'an City, Lushan field survey and collection, and Lushan official government website. 


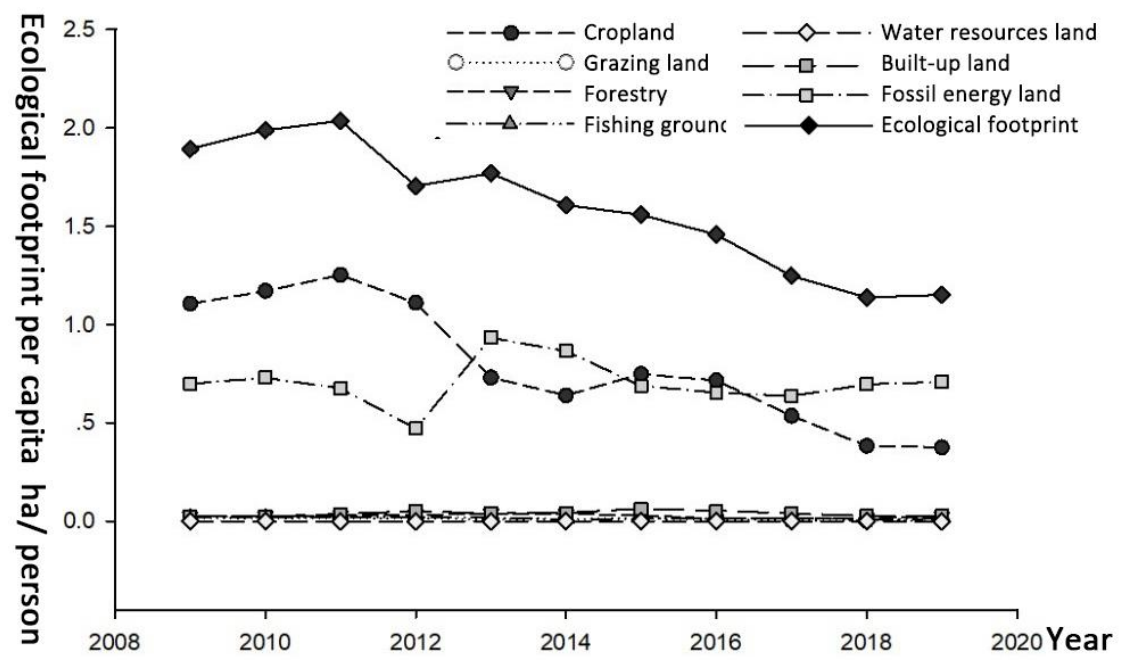

Figure 2. Per capita ecological footprint of Lushan County, 2009-2019, Source: Self-drawn.

As shown in Figure 2, the ecological footprint per capita of Lushan County gradually declined from $1.89 \mathrm{hm}^{2} /$ person in 2009 to $1.15 \mathrm{hm}^{2} /$ person in 2019 , with a slight increase in the total ecological footprint in 2013. It shows that Lushan County focuses on ecological protection and pollution control, thus slowing down ecological footprint consumption. Among the various types of land, construction land and fossil fuel land show a slight upward trend over time, while land dominated by grassland and arable land decreases substantially over time. Changes in the ecological footprint show a positive correlation with human consumption of ecological products and ecological damage. Grassland has seen the most significant decline in ecological footprint per capita, suggesting that the population of Lushan County has changed its diet in recent years, reducing the production and consumption of meat. The ecological footprint of watersheds has also become smaller due to the reduced consumption of fish products. The decline in the ecological footprint of arable land is partly due to changes in the equilibrium factor and reflects the demographic changes in Lushan. The analysis shows that the shift in population and the ecological footprint of arable land per capita is negatively correlated. As the population ages and decreases, the residents' ability to work in agriculture decreases, and their reliance on arable land gradually decreases. The reduction in the ecological footprint of forest land reflects the importance attached by Lushan County to forestry ecological protection over the years and the strengthening of forest supervision, thus reducing the ecological footprint of forest land and promoting ecological protection. The increase in the ecological footprint of construction land and fossil fuel land per capita is mainly due to the rise in electricity consumption in Lushan County.

\subsection{Improved ecological carrying capacity of Lushan County, 2009-2019}

Based on the ecological footprint calculation model, the per capita ecological carrying capacity of Lushan County for all years was calculated as follows (Figure 3 ) 


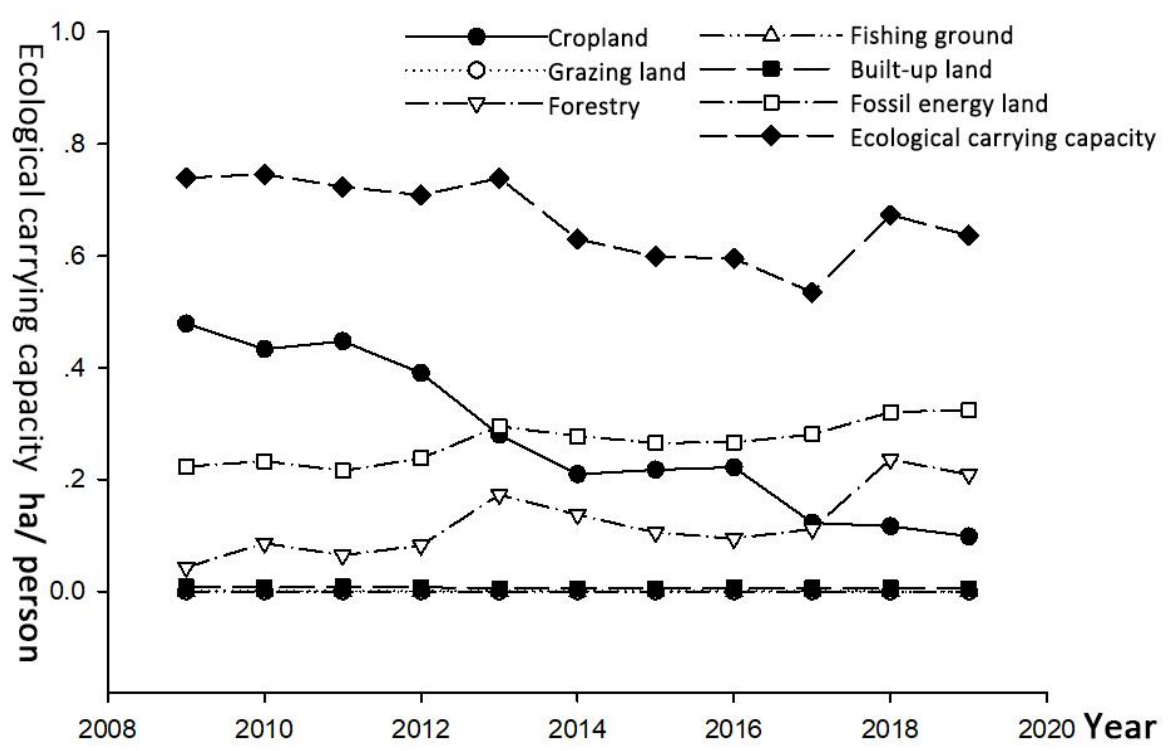

Figure 3. Per capita ecological carrying capacity of Lushan County, 2009-2019, Source: Self-drawn.

As can be seen in Figure 3, the per capita ecological carrying capacity of Lushan County fluctuates and changes, with an overall decrease from $0.73 \mathrm{hm}^{2} /$ person in 2009 to $0.63 \mathrm{hm}^{2} /$ person in 2019 , with the various types of land changing in the following order: forest land $(381 \%)>$ water $(21 \%)>$ fossil fuel land $(45 \%)>$ building land $(-41 \%)>$ grassland $(-33 \%)>$ arable land $(-79)$. Changes in ecological carrying capacity show a positive correlation with land production products and land quality. The decrease of cultivated land ecological footprint is the biggest, indicating the cultivated land in Lushan has been seriously damaged in recent years. Therefore, the ecological protection of Lushan county should first pay attention to the restoration of damaged farmland

The substantial increase in the ecological carrying capacity of forest land indicates that Lushan County is gradually attaching importance to the protection of forest land resources and implementing the policy of returning farmland to forest, as the calculation of fossil fuel land comes from forest land. Hence, the ecological carrying capacity of fossil fuel land also increases. Still, the decrease in construction land and grassland's ecological carrying capacity indicates that Lushan County's land is gradually being destroyed. The ecology is in an unsustainable state and will face the future ecological problem of insufficient carrying capacity.

\subsection{Ecological surplus and deficit of Lushan County in 2010-2017}

Based on the above formula, calculate the ecological deficit (surplus) of Lushan County from 2009-2019 (Figure 4) 


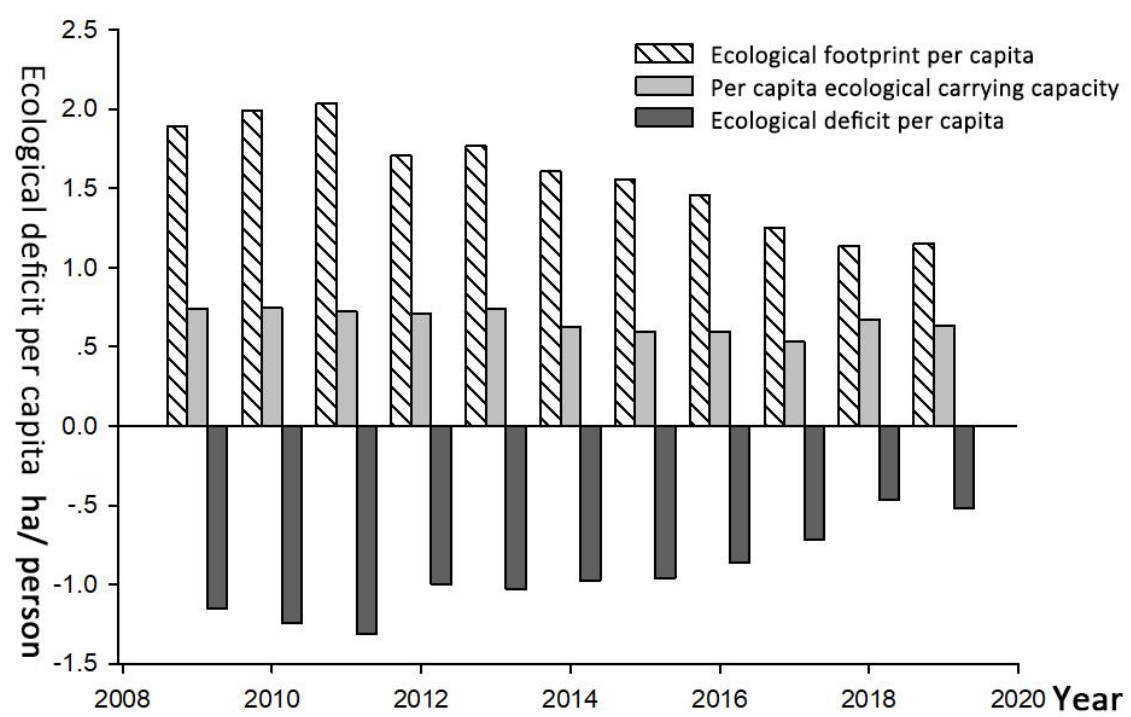

Figure 4. Per capita ecological deficit of Lushan County, 2009-2019, Source: Self-drawn.

From Figure 4, it can be seen that the pressure brought by economic development in Lushan County far exceeds the ecological carrying capacity. Lushan County as a whole showed an ecological deficit of -1.15 $\mathrm{hm}^{2} /$ person in 2009 and $-0.52 \mathrm{hm}^{2} /$ person in 2019, with the ecological debt decreasing by more than $55 \%$ and its degree of ecological deficit gradually reducing. It shows that Lushan County has done some measures in ecological protection but is still in ecological debt in 2019. Most of the ecologically productive land in Lushan is in an unsustainable state. It reflects that Lushan is currently in a state of ecological imbalance and has poor sustainability of ecological development.

\section{Prediction of the development trend of ecological footprint}

Since the ecological footprint model only calculates the productive land consumption in a specific period, it isn't easy to reflect the corresponding economic and social system dynamics. Due to the time series defects of the ecological footprint model itself, this paper tries to make a short-term prediction of the ecological restoration in Lushan County after the disaster, to better understand the development trend of the ecological construction in the hard-hit areas after the disaster and predict the development trend of the ecological footprint in the future. SPSS software was used to construct the regression equation of per capita ecological footprint and per capita ecological carrying capacity, trying to understand the ecological restoration situation in Lushan county in the future $(G u o, 2008)$. Regression analysis is the main method to predict the index of ecological footprint and ecological carrying capacity.

\subsection{Prediction of ecological footprint per capita}

Taking Lushan County as an example, the ecological footprint y stands for the dependent variable in the regression model, the year $x$ stands for the independent variable, and 2010 is the base year to construct different ecological footprint prediction models. 


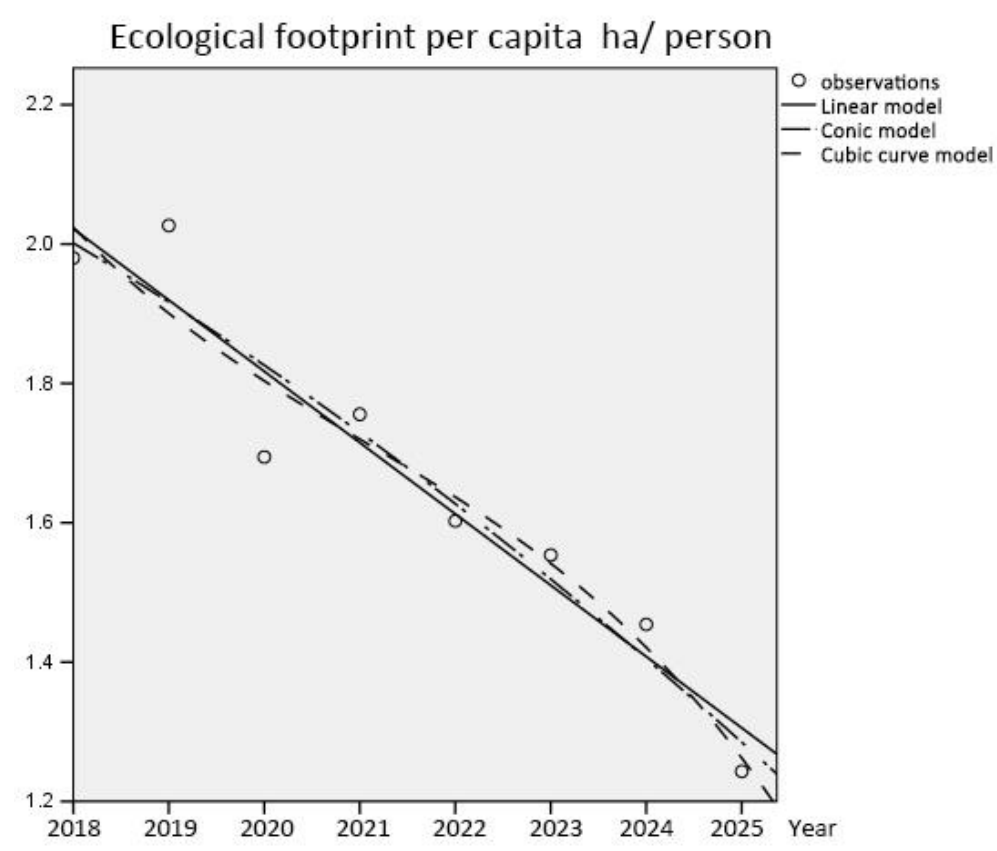

Figure 5. Ecological footprint model fitting of Lushan County, Source: Self-drawn.

As shown from Figure 5, combining the goodness of fit (R2) and the significance of the regression coefficient, the unary regression equation is selected as the model equation, which has higher goodness of fit. In connection with the ecological factors and economic factors of the above post-disaster ecological evaluation model, this paper considers the impact on the ecological footprint of social and economic factors such as $\mathrm{Wu}$ correlation analysis of least-square method research $(\mathrm{Wu}, 2006)$. The model of the dependent variable is set to the per capita GDP variable $(z)$ and year (variable $x$ ), the independent variable is set to the variables (y). The annual growth rate of per capita GDP is set to be $8 \%$, referring to the 13th Five-Year Plan of $\mathrm{Ya}$ ', an the following regression prediction equation can be obtained:

$$
y=2.43-0.046 x+0.018 x-0.237 z \quad \text { Adjusted } \mathrm{R}^{2}=0.929
$$

According to the present development model, the ecological footprint of Lushan County has been gradually decreasing over the years, which proves that the ecological pressure is slowly reducing and the ecology is developing towards a sustainable direction.

\subsection{Prediction of per capita ecological carrying capacity}

Similar to the calculation of per capita ecological footprint, the dependent variable of the regression model is the ecological carrying capacity $y$, the independent variable is the year $x$, and 2010 is taken as the base year $(x=1)$ to build different types of ecological footprint prediction models (Figure 6 ). 


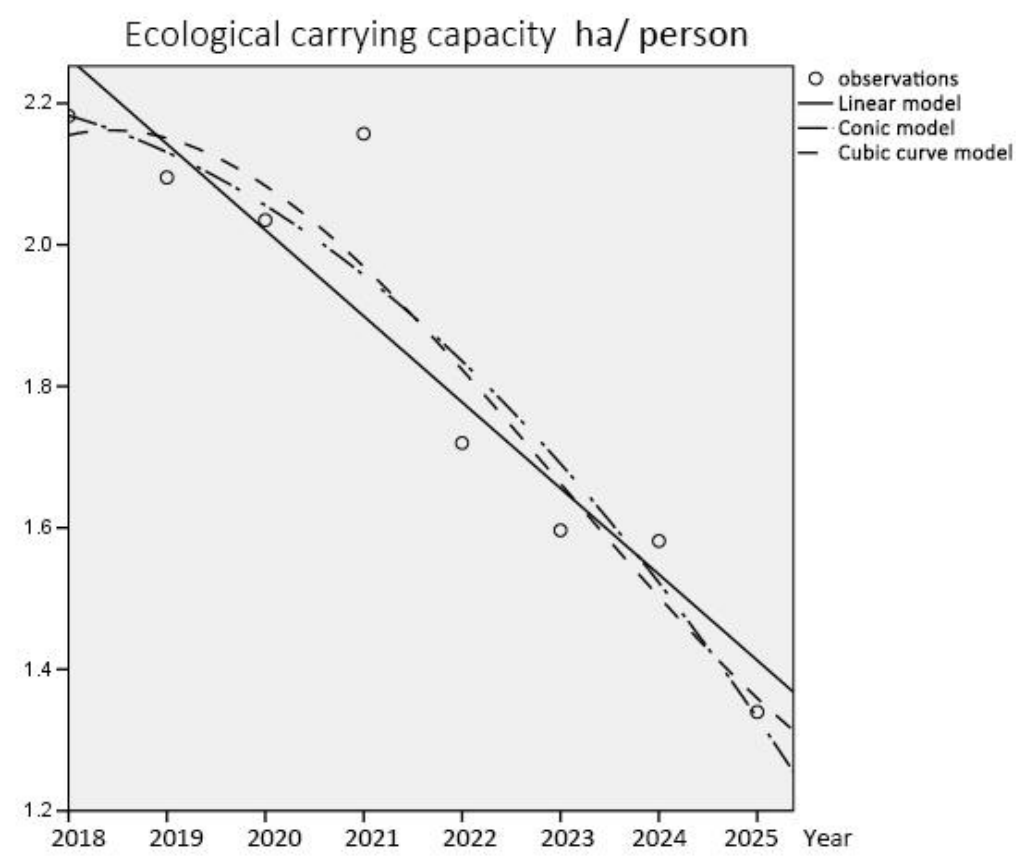

Figure 6. Ecological carrying capacity model fitting of Lushan County, Source: Self-drawn.

As shown from Figure 6, comparing the goodness of fit (R2) of the three curves, the conic curve has the highest degree of fit among the three models, followed by the linear curve and cubic curve. However, in the analysis of variance and the significance test of the regression coefficient of the quadratic curve, the regression coefficient is not significant, and the calculated probability value is 0.844 and 0.252 , respectively, which are both more excellent than the significance level. Therefore, without considering the conic curve model, the unitary linear equation is selected as the model equation, with a high degree of goodness of fit. Same as the calculation of ecological footprint, the per capita GDP variable (z) and year (variable $\mathrm{x}$ ) as the independent variables of the regression model, to ecological footprint as the dependent variable $y$, the per capita GDP forecast of the reference Ya'an much starker choices-and graver consequences-in planning, increasing at an average annual rate of $8 \%$, the final selection of regression equation as follows:

$$
y=1.001+0.008 \cdot \mathrm{x}-0.159 \cdot z \quad \text { Adjusted } \mathrm{R}^{2}=0.912
$$

According to the above regression results, the per capita ecological footprint is predicted, and the change of Lushan County in the next five years is shown in the following table (Figure 5.70).

Table 1. Prediction of Future Ecological Footprint of Lushan County, Source: Self-drawn.

\begin{tabular}{cccc}
\hline Year & $\begin{array}{c}\text { Forecast per capita ecological } \\
\text { footprint }\end{array}$ & $\begin{array}{c}\text { Forecast per capita ecological } \\
\text { carrying capacity }\end{array}$ & $\begin{array}{c}\text { Forecast per capita } \\
\text { ecological deficit/surplus }\end{array}$ \\
\hline 2021 & 0.80 & 0.38 & -0.43 \\
2022 & 0.67 & 0.33 & -0.35 \\
2023 & 0.53 & 0.27 & -0.26 \\
2024 & 0.39 & 0.21 & -0.17
\end{tabular}


The result shows that the ecological footprint of Lushan county will still be in the state of ecological deficit in the future because the ecological footprint and the ecological carrying capacity are both decreasing. As for ecological footprint, according to the current development trend, the consumption of ecological resources in Lushan County will gradually decrease, and the ecological pressure will gradually decrease. The ecological deficit is also steadily reduced, and the overall ecological environment is slowly transferred to a sustainable state. However, according to the current development model, the ecological carrying capacity of Lushan County is also gradually decreasing. If the ecological environment is not protected, the productive land will degenerate progressively, and the equilibrium and yield factors will reduce. And in the long term, the ecology will be in a state of imbalance.

Therefore, Lushan County should improve the damaged state of ecology from two aspects. One is to improve the ecological carrying capacity; the other is to maintain the current trend of the decline of ecological footprint. Only in this way can we effectively curb the continuous deterioration of ecology in the worst-hit areas. Thus, it is necessary to build an intelligent town for disaster prevention and mitigation, strengthen the construction of restoration projects and improve relevant laws to improve the regional ecological restoration.

\section{Conclusions}

This paper constructs an ecological footprint model by data correction of the ecological footprint, expanding the calculation categories, localizing and improving the traditional ecological footprint model, and predicting the future ecological footprint development and sustainability status. The results show the overall ecological footprint of Lushan County has gradually decreased between 2009 and 2019, from $1.89 \mathrm{hm}^{2}$ to $-1.15 \mathrm{hm}^{2}$, a $39 \%$ reduction. However, the ecological carrying capacity has deteriorated, from $0.73 \mathrm{hm}^{2}$ in 2009 to $0.63 \mathrm{hm}^{2}$ in 2019 , a decrease of $14 \%$. As Lushan County promotes environmental protection measures such as "returning farmland to the forest", the gap between the overall ecological footprint and carrying capacity of Lushan County is gradually narrowing, and the ecological deficit is slowly decreasing.

In the future, the ecological footprint of Lushan County will remain in a state of ecological deficit. The reason for this is that both the ecological footprint and the ecological carrying capacity are declining. In terms of the ecological footprint, according to the current development trend, Lushan County's consumption of ecological resources will gradually become less, and the ecological pressure will gradually decrease. The ecological deficit is also shrinking progressively, and the overall ecological environment is slowly moving towards a sustainable state. However, according to the current development pattern, the ecological carrying capacity of Lushan County is also gradually becoming smaller, indicating that if not protected, the ecologically productive land will degrade progressively. The equilibrium and yield factors will become gradually smaller, leaving the ecology in a state of imbalance in the long run.

Therefore, Lushan County should start from two aspects to improve the damaged state of ecology after the disaster. One is to improve the ecological carrying capacity, and the other is to maintain the existing declining trend of ecological footprint. Only then can the continued deterioration of the ecology in the hardest-hit areas after the disaster be effectively curbed. To this end, ecological restoration in the region should be improved by establishing smart towns for disaster prevention and mitigation, strengthening restoration projects, and improving relevant laws. 


\section{References}

Sadik, N. (1997). 'Women, population and sustainable development in South Asia', Journal of International Affairs, 147-168.

Victor, P. (2010). 'Questioning economic growth'. Nature, 468(7322), 370-371.

An, N., Huang, M. L., \& Ma, Q. (2019). 'Evaluation and influence mechanism of traffic environment in small and medium-sized mountain towns'. Architecture and Culture, 000(007), 197-198.

Mikulčić, H., Wang, X., Duić, N., \& Dewil, R. (2020). 'Environmental problems are arising from the sustainable development of energy, water and environment system'. Journal of environmental management, 259, 109666.

Zêzere, J. L., de Brum Ferreira, A., \& Rodrigues, M. L. (1999). 'The role of conditioning and triggering factors in the occurrence of landslides: a case study in the area north of Lisbon'

(Portugal). Geomorphology, 30(1-2), 133-146.

Wackernagel, M., \& Rees, W. (1998). 'Our ecological footprint: reducing human impact on the earth' (Vol. 9). New society publishers.

Wackernagel, M., \& Yount, J. D. (1998). 'The ecological footprint: an indicator of progress toward regional sustainability' . Environmental Monitoring and Assessment, 51(1), 511-529.

Niccolucci, V., Bastianoni, S., Tiezzi, E. B. P., Wackernagel, M., \& Marchettini, N. (2009). 'How deep is the footprint? A 3D representation'. Ecological Modelling, 220(20), 2819-2823.

Xu, Z. M., Zhang, Z. Q., Cheng, G. D., \& Chen, D. J. (2003). 'China's 1999 ecological footprint calculation and development capacity analysis'. Chinese Journal of Applied Ecology (02), 121-126.

Haberl, H., Wackernagel, M., Krausmann, F., Erb, K. H., \& Monfreda, C. (2004). 'Ecological footprints and human appropriation of net primary production: a comparison'. Land use policy, 21(3), 279-288.

Wang, L. (2011). 'Ecological security assessment of Yancheng City based on ecological footprint'. Land and Natural Resources Research (01), 59-61.

Yang, G. H., \& Li, P.(2007). 'The theoretical significance of ecological tourism footprint'. Chinese Journal of Tourism (02),54-58.

Wu, Z. F., Hu, Y. H., Li, D. Q., \& Kuang, Y. Q. (2006). 'Analysis and simulation of urban water ecological footprint change'. Resources Science, 28(5), 152-156.]

Barrett, J., \& Simmons, C. (2003). 'An ecological footprint of the UK: Providing a tool to measure the sustainability of local authorities'. York: Stockholm Environment Institute, University of York.

Wiedmann, T., Minx, J., Barrett, J., \& Wackernagel, M. (2006). 'Allocating ecological footprints to final consumption categories with input-output analysis'. Ecological economics, 56(1), 28-48.

Shut'ko, L., Samorodova, L., Ivanov, A., (2020). 'Ecological footprint and decoupling in the sustainable development of a region'. E3S Web of Conferences, 174(3), 04058.

Huang, L.N. et al. (2008) ' Calculation method of the ecological footprint of water resources ', Journal of Ecology, 31 (04), pp. 502-509.

Liu, J. X., Wang, Q., Gu, X. W., Li, G. J., \& Sun, P. (2007). 'Regional ecological footprint based on "national hectare": A case study of three provinces in Northeast China.'

Liu, M.C.(2010) ' Temporal dynamics and spatial patterns of China's ecological footprints ', Graduate School of Chinese Academy of Sciences, 2010(1), pp. 49-53.

Zhao, X.G. et al.(2006) ' Design of sustainability indicators system based on ecological footprint ', Scientia Agricultura Sinica, 39(6), pp. 1202-1207.

Su, F.H. et al. (2013) ' Rockfall and landslide susceptibility assessment in Lushan earthquake region ', Journal of Mountain Science, 31 (04), pp. 502-509.

Guo, Z.F., Zhao, T.D., \& Huang, X.B. (2008). 'Evaluation of sustainable development in Anhui Province based on ecological footprint theory'. Future and Development, 000(010), 63-66

Wu, K.Y., \& Wang, L.J. (2006). 'A partial least squares regression model for ecological footprint and its impact factors'. Resources Science, 28(6), 182-188. 